CONGENITAL HEART DISEASE

\title{
Transcatheter closure of patent ductus arteriosus with severe pulmonary arterial hypertension in adults
}

\author{
C Yan, S Zhao, S Jiang, Z Xu, L Huang, H Zheng, J ling, C Wang, W Wu, H Hu, G Zhang, Z Ye, \\ H Wang
}

See end of article for authors' affiliations

......................

Correspondence to: Professor S Zhao, Department of Radiology, Fuwai Hospital, 167 Beilishi Road, Beiiing 100037, China; cjr.zhaoshihua@vip. 163.com

Accepted 27 June 2006 Published Online First 5 September 2006
Background: Surgical closure of patent ductus arteriosus (PDA) with severe pulmonary arterial hypertension in adults carries higher risk than in children.

Objectives: To investigate the application of self-expandable occluders for transcatheter closure of PDA associated with severe pulmonary arterial hypertension in adults, and the assessment of immediate and shortterm results.

Methods: 29 adult patients (6 men, 23 women) underwent attempted transcatheter closure of PDA at a mean (standard deviation (SD)) age of 31.1 (11.4) years (range 18-58 years) and a mean (SD) weight of 54.1 (7.1) kg (range 42-71 kg). On the basis of haemodynamic and clinical data obtained before and after trial occlusion, the final duct occlusion was determined and carried out. Radiographs of the chest, electrocardiograms and echocardiograms were used for follow-up evaluation of the treatment within 1 day, 1 month and 3-6 months after successful closure.

Results: 20 of the 29 patients had successful occlusion (group 1), and 9 patients failed (named group 2). In group 1, in which occlusion was successful, mean (SD) pulmonary arterial pressures decreased markedly after trial occlusion: 78 (19.3) mm Hg (range 50-125 mm Hg) before occlusion and 41 (13.8) $\mathrm{mm} \mathrm{Hg}$ (range 23-77 mm Hg) after occlusion. Systemic arterial oxygen saturation was found to be $>90 \%$ in 19 patients and $<90 \%$ in the remaining patient before inhalation of oxygen, and $>95 \%$ during inhalation of oxygen or after occlusion in all 20 patients. In group 2, the occlusion was not successful, because in two patients the device was not available; another two patients showed worsening of symptoms. The other five patients showed increased pulmonary arterial pressures after trial closure; their mean (SD) pulmonary arterial pressures increased by $10.3(6) \mathrm{mm} \mathrm{Hg}(4-16 \mathrm{~mm} \mathrm{Hg})$ after trial occlusion, and systemic arterial oxygen saturation was $85.5 \%(2.6 \%$ ) (range $82.6-88 \%$ ) before inhalation of oxygen and $94.7 \%$ (1.7\%) (range 90.7 $99.1 \%$ ) during inhalation of oxygen. In group 1, the dimensions of the left atrium, left ventricle and pulmonary artery increased considerably in 3-6-months of follow-up compared with those of preocclusion.

Conclusions: Transcatheter closure is an effective treatment for adults with PDA associated with reversible severe pulmonary arterial hypertension. Further research is needed for the evaluation of long-term results.
$\mathrm{P}$ atent ductus arteriosus (PDA) associated with severe pulmonary arterial hypertension in adults has become a challenge for cardiologists, and the risk of surgical ligament is high for known complications. In these patients, the reversibility of severe pulmonary arterial hypertension determines management and prognosis. With the development of techniques and occluders, transcatheter closure of PDA becomes increasingly frequent in children and adolescents. ${ }^{1-10}$ As temporary occlusion of the duct in catheterisation is one of the methods that can be applied to determine preoperatively the degree of reversibility of pulmonary arterial hypertension, transcatheter closure of PDA with severe pulmonary arterial hypertension is attempted in children (aged 5-12 years), and success has been achieved. ${ }^{11}$ To our knowledge, however, no group reports can be found on whether PDA associated with severe pulmonary arterial hypertension in adults can be treated by this method. In this study, we used self-expandable occluders to close PDA associated with "reversible" severe pulmonary arterial hypertension in adults, and assessed the immediate and short-term results.

\section{PATIENTS AND METHODS \\ Patients}

From May 1998 to May 2005, 29 adult patients (6 men and 23 women), who were diagnosed with PDA associated with severe pulmonary arterial hypertension, underwent attempted transcatheter closure of PDA. Informed consent was obtained from each patient. All patients had clinical and echocardiographic findings of a PDA, and mean (standard deviation (SD)) pulmonary arterial pressures measured by a catheter were $>50 \mathrm{~mm} \mathrm{Hg}$. The median (SD) age of patients was 31.1 (11.4) years (range 18-58 years) and the mean (SD) body weight was 54.1 (7.1) kg (range 42-71 kg). All patients were symptomatic: dyspnoea on physical exertion $(n=29)$; cyanosis $(\mathrm{n}=5)$; hoarseness $(\mathrm{n}=2)$; and haemoptysis $(\mathrm{n}=1)$. All patients had left atrial and ventricular volume overload documented by echocardiography.

\section{Device design}

In this study, two types of occluder are used. One is the Amplatzer duct occluder (ADO, AGA Medical Corporation, Golden Valley, Minnesota, USA). As the maximum size of the ADO is $16 / 14 \mathrm{~mm}$ and this is too small for large PDA up to $11 \mathrm{~mm}$, another type of occluder, the Amplatzer muscular ventricular septal defects occluder (AMVSDO), is used. The device design of these two types has been described in detail in previous reports. $^{6}{ }^{11}$

Abbreviations: ADO, Amplatzer duct occluder; AMVSDO, Amplatzer muscular ventricular septal defects occluder; PDA, patent ductus arteriosus; SAsat, systemic arterial oxygen saturation 


\section{Procedure}

The technique of transcatheter closure of PDA using ADO and AMVSDO was similar to that described in previous reports. ${ }^{6}{ }^{11}$ After percutanous puncture of the femoral artery and vein, all patients underwent routine right and left heart catheterisation, and complete haemodynamic data on each cardiac chamber and great artery were obtained. The descending aortogram in lateral or right anterior oblique view was performed with a 6 French pigtail catheter (Cordis, Miami, Florida, USA) to define the size and anatomy of PDA (figs 1A, 2A). Then, the patients were required to breathe oxygen $\left(\mathrm{FiO}_{2}>0.5\right)$ using a facemask for $10 \mathrm{~min}$, and haemodynamic measurements were repeated during inhalation of oxygen, especially for measurement of pulmonary arterial pressure and aortic pressure.

The next step was "trial occlusion". The size of the occlusion device that we chose was 4-10 mm larger than the narrowest size of the PDA, which was measured by a descending aortogram. After screwing it to the delivery cable, the occluder was pulled into the loader and was introduced into the guiding sheath. Under fluoroscopic guidance, the occluder was deployed and pulled gently against the aortic ampulla. Then, the rest of the occluder was deployed into the PDA. Changes in haemodynamic and clinical data were recorded while the device was still attached to the cable; we called this step trial occlusion.

For each patient, trial occlusion was performed and it lasted about $30 \mathrm{~min}$ so that we could obtain the changes in haemodynamic and clinical data. On the basis of the above information, we determined whether or not the occluder should be released finally. The criteria that we followed were: (1) a fall in the pulmonary artery pressure or no elevation; (2) no decrease in the aortic pressure; and (3) no worsening of signs and symptoms. If all the criteria were satisfied, we considered the pulmonary arterial hypertension to be reversible. Otherwise, it was considered to be irreversible pulmonary arterial hypertension, and occlusion was abandoned.

The device could be released after $30 \mathrm{~min}$ if the above criteria were met, and a repeat descending aortogram (figs 1B, 2B) excluded moderate-to-large residual left-to-right shunt. Otherwise, it should be retracted into the delivery sheath. Prophylactic antibiotics were routinely given after the procedure for 3 days. All patients returned home after 2 days of observation in the heart ward.

\section{Follow-up}

For each patient, a chest radiograph, an electrocardiogram and an echocardiogram were recorded at 1 day, 1 month, and serially at 3-6-month intervals.

\section{Statistical analysis}

The data in the study were expressed as mean (SD), and range was also provided. The results before and after occlusion were compared using paired-samples $\mathrm{t}$ tests, and $\mathrm{p}<0.05$ was considered significant. Statistical software used in this study was SPSS V.10.

\section{RESULTS}

\section{Patients in whom transcatheter closure was achieved}

Closure was achieved in 20 of the 29 adult patients; table 1 shows their clinical and haemodynamic data. The mean diameter of the PDA was $10.4(2.7) \mathrm{mm}$ (range 6-16 mm). The diameter of the occluder was $15.6(3.2) \mathrm{mm}(10-20 \mathrm{~mm})$. According to the classification, ${ }^{12} 14$ patients with PDA belong to type A and 6 patients with PDA belong to type C. The mean (SD) pulmonary:systemic flow ratio (Qp:Qs) was 2.1 (0.9; range 1.02-4.38). The mean pulmonary vascular resistance was 9.1 (5.3) Woods units before inhalation of oxygen. The systolic pulmonary arterial pressure decreased significantly after closure ( 104.9 (27.4) v 56.3 (18.3) $\mathrm{mm} \mathrm{Hg}, \mathrm{p}<0.05$ ), and so was the mean (SD) pulmonary arterial pressure $(78$ (19.3) $v 41(13.8) \mathrm{mm} \mathrm{Hg}, \mathrm{p}<0.05)$. Before inhalation of oxygen, the systemic arterial oxygen saturation (SAsat) was $93.5 \%(2.1 \%)$, and the SAsat increased to $96.5 \%$ $(1.5 \%)$ after trial occlusion. There was a significant decrease in pulmonary vascular resistance after inhalation of oxygen in these patients as well. Four patients had trace angiographic residual shunt, which disappeared 2 days later. No other complications occurred in the procedure. The mean (SD) fluoroscopy time was 31.6 (8.9) $\mathrm{min}$.

Patients in whom transcatheter closure was abandoned Nine patients (six type A, two type B and one type C) failed to take the final occlusion in the study, and table 2 shows their clinical and haemodynamic data. Five patients had incresed pulmonary arterial pressure after trial occlusion, and their mean (SD) Qp:Qs was 1.01 (0.34) before inhalation of oxygen and $1.43(0.8)$ during inhalation of oxygen. Pulmonary vascular resistance was 22.4 (6.4) Woods units before inhalation of oxygen and 15.8 (5.7) Woods units after inhalation of oxygen. Two patients had large residual shunt, and another two patients showed worsening of dyspnoea.

\section{Follow-up}

Within the follow-up of 3-6 months, the signs and symptoms had improved markedly in all 20 patients. The radiograph of the chest showed diminution in heart size and pulmonary vascularity after 3-6 months, and the mean (SD) cardiothoracic
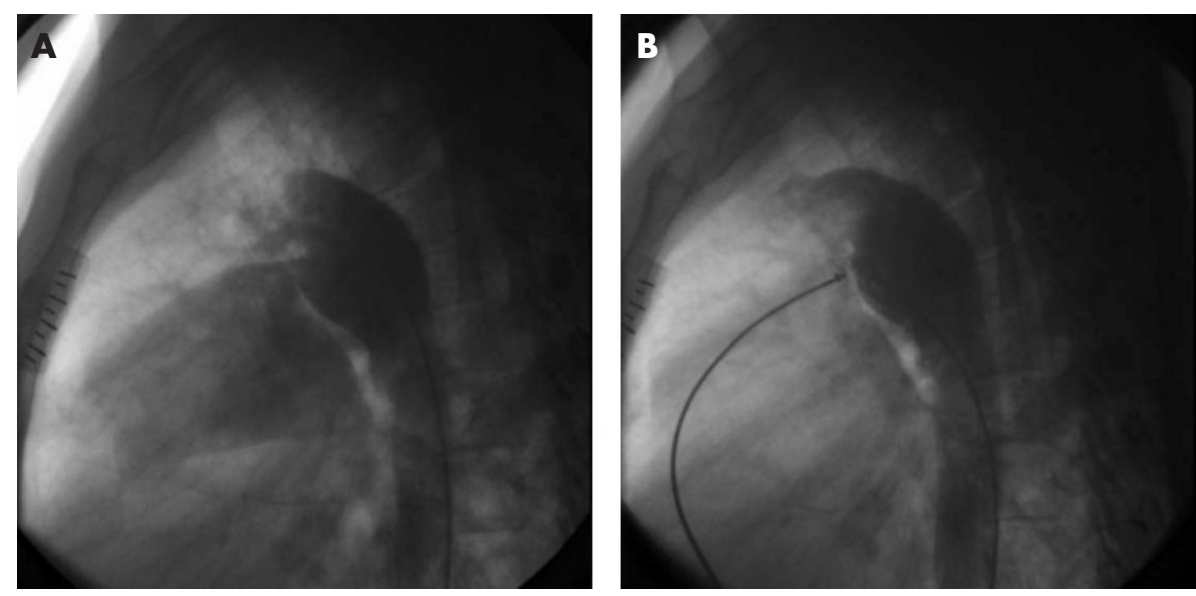

Figure 1 Descending aortogram in lateral view (A) and a repeat aortogram after duct occlusion with ADO (B). 

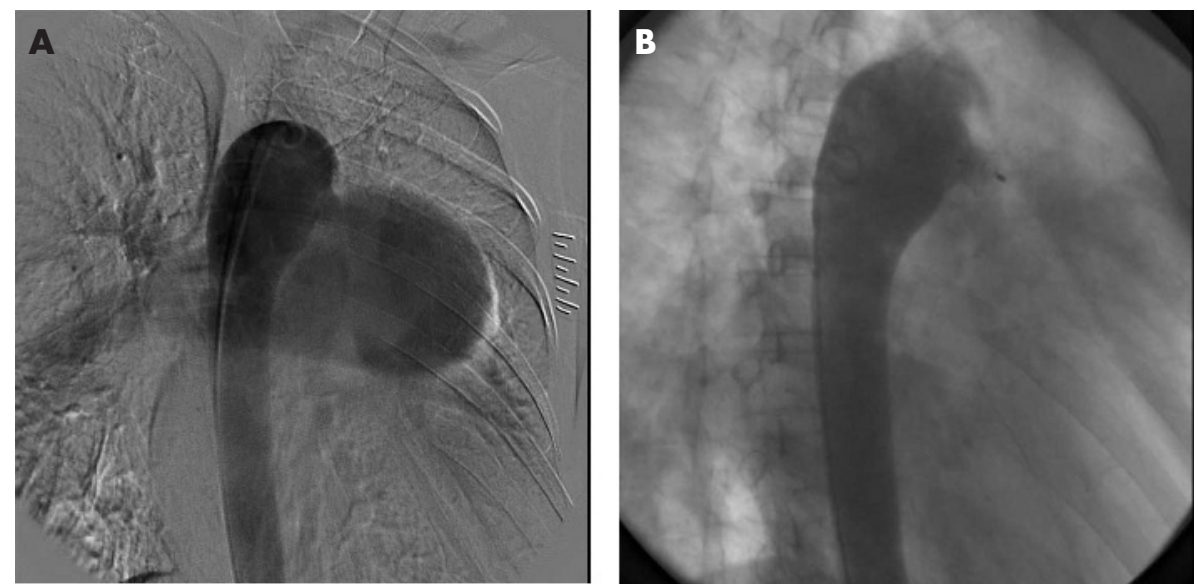

Figure 2 Descending aortogram in right anterior oblique view (A), and a repeat aortogram after duct occlusion with AMVSDO (B). Residual shunt through the device can be found, and it disappeared the next day after occlusion. The narrowest diameter of PDA is $12 \mathrm{~mm}$, and an 18-mm AMVSDO was selected.

ratio decreased significantly $(58.7 \%(3.1 \%) \vee 53.9 \%(3.5 \%)$, $\mathrm{p}<0.05)$. No new arrhythmias were found in the follow-up of the electrocardiogram. Echocardiography indicated that no residual shunt occurred during the 3-6-month follow-up, and there was a significant decrease in the left atrium dimension (36.2 (10.3) v $28.8(8.3) \mathrm{mm}, \mathrm{p}<0.05)$, left ventricular diastolic internal dimension $(58.3$ (12.5) v 49.3 (11.5) $\mathrm{mm}, \mathrm{p}<0.05)$, right ventricular diastolic internal dimension (21.1 (7.3) $v 17$ (4.3) $\mathrm{mm}, \mathrm{p}<0.05)$ and the diameter of the main pulmonary artery $(32.7(10.4) \vee 27.6(10.8) \mathrm{mm}, \mathrm{p}<0.05)$.

\section{DISCUSSION}

Adult patients with PDA are not easily detected, and are seen by cardiologists only when the signs and symptoms are severe. PDA occurs more often in developing countries, where some of the patients, especially those with large PDA, have severe pulmonary arterial hypertension. In this condition, the most important determinant of management and prognosis is whether the severe pulmonary arterial hypertension is reversible. The advent of duct occlusion allows non-surgical closure of PDA at cardiac catheterisation, which has the potential to differentiate from the reversibility of severe pulmonary arterial hypertension. Compared with the surgical closure of adult PDA, transcatheter closure can not only correct a haemodynamic defect but can also differentiate from the reversibility of pulmonary arterial hypertension. Among the methods that can be used to determine preoperatively the degree of reversibility, we believe that temporary occlusion of the duct is reliable, because it can be used to assess the consequences of duct closure and thereby evaluate the reversibility of severe

Table 1 Clinical and haemodynamic data of successful occlusion in patients $(n=20)$

\begin{tabular}{|c|c|c|c|c|c|c|c|c|c|c|c|c|c|c|c|}
\hline \multirow{2}{*}{\multicolumn{2}{|c|}{$\begin{array}{l}\text { Patient numberAge } \\
\text { (n) } \quad \text { (years) }\end{array}$}} & \multirow[b]{2}{*}{$\begin{array}{l}\text { Weight } \\
\text { (kg) }\end{array}$} & \multicolumn{3}{|c|}{ SAsat (\%) } & \multicolumn{3}{|c|}{$\begin{array}{l}\text { Pulmonary arterial pressure }(S(M)) \\
\text { mm Hg }\end{array}$} & \multicolumn{2}{|c|}{$\begin{array}{l}\text { Aortic pressure [S(M)] } \\
\mathrm{mm} \mathrm{Hg}\end{array}$} & & \multicolumn{2}{|c|}{ Rp (Wood) } & \multirow{2}{*}{$\begin{array}{l}\text { Duct } \\
\text { diameter } \\
(\mathrm{mm})\end{array}$} & \multirow{2}{*}{$\begin{array}{l}\text { Occluder } \\
\text { diameter } \\
(\mathrm{mm})\end{array}$} \\
\hline & & & $\begin{array}{l}\text { Before } \\
\mathrm{O}_{2}\end{array}$ & $\begin{array}{l}\text { During } \\
\mathrm{O}_{2}\end{array}$ & $\begin{array}{l}\text { After } \\
\text { closure }\end{array}$ & Before $\mathrm{O}_{2}$ & During $\mathrm{O}_{2}$ & After closure & e Before O2 & After closure & $Q p / Q s$ & $\begin{array}{l}\text { Before } \\
\mathrm{O} 2\end{array}$ & $\begin{array}{l}\text { During } \\
\mathrm{O} 2\end{array}$ & & \\
\hline 1 & 41 & 58 & 95.5 & 99 & 96.4 & $75(55)$ & 74 (53) & 40 (30) & $170(100)$ & 190 (120) & 2.5 & 5.24 & 2.32 & 7 & 10 \\
\hline 2 & 20 & 45 & 95.7 & 100 & 98.2 & 67 (53) & 62 (46) & 45 (28) & 140 (92) & 152 (101) & 4.38 & 1.43 & 0.93 & 6 & 12 \\
\hline 3 & 24 & 53 & 96.9 & 100 & 98 & $110(75)$ & $107(70)$ & 43 (32) & $144(90)$ & 160 (105) & 2.52 & 2.67 & 0.86 & 16 & 20 \\
\hline 4 & 35 & 63 & 95.5 & 99 & 97.3 & $118(85)$ & $115(80)$ & $50(36)$ & $143(86)$ & 180 (118) & 1.7 & 11.2 & 8.11 & 10 & 16 \\
\hline 5 & 18 & 53 & 96.4 & 100 & 100 & 94 (77) & 89 (73) & 51 (35) & 125 (98) & 135 (107) & 1.23 & 9.33 & 0.53 & 8 & 14 \\
\hline 6 & 58 & 57 & 96.4 & 100 & 96 & $75(50)$ & 74 (48) & $36(26)$ & 197 (127) & 188 (144) & 2.97 & 4.81 & 2.43 & 6 & 10 \\
\hline 7 & 54 & 60 & 94.6 & 98.6 & 96.2 & $76(62)$ & $75(60)$ & 42 (31) & 149 (104) & 162 (120) & 2.37 & 8.35 & 6.3 & 11 & 18 \\
\hline 8 & 38 & 45 & 92.2 & 97.8 & 95 & $85(70)$ & $80(61)$ & $40(30)$ & $120(80)$ & $130(100)$ & 2.25 & 8.3 & 7.55 & 9 & 14 \\
\hline 9 & 35 & 66 & 94.1 & 99.2 & 98.8 & $170(125)$ & $153(111)$ & 104 (77) & 174 (124) & 190 (147) & 1.28 & 17.01 & 15.31 & 14 & 18 \\
\hline 10 & 22 & 47 & 93 & 100 & 96.5 & $90(80)$ & 85 (72) & 61 (46) & 139 (87) & $156(108)$ & 1.68 & 6.78 & 6.16 & 11 & 14 \\
\hline 11 & 18 & 53 & 92.8 & 97.4 & 96.3 & $128(103)$ & $110(91)$ & 49 (36) & 135 (110) & 160 (112) & 1.5 & 13.07 & 7.22 & 13 & 20 \\
\hline 12 & 25 & 62 & 90.2 & 97 & 96.2 & $110(86)$ & $99(76)$ & $84(60)$ & 110 (89) & 119 (98) & 1.12 & 14.17 & 6.57 & 12 & 18 \\
\hline 13 & 48 & 45 & 93 & 100 & 96.7 & $70(55)$ & 60 (44) & 35 (23) & 154 (92) & $166(100)$ & 2 & 2.59 & 2.49 & 11 & 14 \\
\hline 14 & 39 & 52 & 91.8 & 95.5 & 94 & 88 (63) & $86(63)$ & $54(40)$ & 132 (83) & 159 (117) & 3.64 & 5.63 & 2.95 & 11 & 18 \\
\hline 15 & 43 & 65 & 91.8 & 96.3 & 95 & $100(70)$ & $100(70)$ & $65(45)$ & $125(90)$ & 147 (103) & 1.5 & 8.11 & 7.43 & 8 & 12 \\
\hline 16 & 45 & 71 & 92.8 & 97.8 & 95.3 & $120(80)$ & $110(75)$ & $50(37)$ & 160 (105) & 190 (115) & 2.5 & 5.48 & 4.29 & 10 & 20 \\
\hline 17 & 40 & 43 & 92.5 & 97.6 & 95.6 & 130 (81) & $69(49)$ & 57 (45) & $125(95)$ & $123(96)$ & 1.62 & 16.1 & 10.64 & 14 & 16 \\
\hline 18 & 25 & 59 & 91.6 & 98 & 95.2 & $122(96)$ & $118(90)$ & $80(60)$ & 130 (102) & 148 (114) & 1.3 & 10.38 & 9.78 & 12 & 18 \\
\hline 19 & 34 & 53 & 94.5 & 98 & 97.4 & 139 (99) & $123(94)$ & $60(46)$ & 152 (106) & 150 (109) & 2.44 & 9.47 & 6.31 & 10 & 16 \\
\hline $20 \Delta$ & $\begin{array}{l}22 \\
22\end{array}$ & 42 & 89.4 & 93.3 & 95 & $120(86)$ & $120(84)$ & $80(57)$ & $122(98)$ & 140 (104) & 1.06 & 22.2 & 21.03 & 8 & 14 \\
\hline \multirow[t]{4}{*}{ Total $(n)=20$} & & & & & & & & S56.3 & S142.3 & S157.3 & & & 6.5 & & \\
\hline & (12.1) & $(8) 4$. & $(2.1)$ & $(1.8)$ & (1.5) & $(27.4)$ & $(24.1)$ & (18.3) & $(21.2)$ & $(22.1)$ & $(0.9)$ & (5.3) & $(5.1)$ & $(2.7)$ & (3.2) \\
\hline & & & & & & M78 (19.3) & M70.8 & M41 (13.8) & M97.9 & M111.9 & & & & & \\
\hline & & & & & & & (18.2) & & (12.4) & (13.7) & & & & & \\
\hline
\end{tabular}

SAsat, systemic arterial oxygen saturation; S, systolic arterial pressure; $M$, mean arterial pressure; $Q p / Q s$, the ratio of pulmonary blood flow to systemic blood flow; Rp, pulmonary vascular resistance. $\boldsymbol{\Delta}$, associated with mild tricuspid regurgitation. Before $\mathrm{O}_{2}$, before oxygen inhalation; During $\mathrm{O}_{2}$, during oxygen inhalation; After occlusion, after trial occlusion; Occluder diameter: the narrowest segment of occluder (the pulmonary segment of ADO and the waist of AMVSDO). Values are given as mean (SD). 
Table 2 Clinical and haemodynamic data of unsuccessful occlusion patients $(n=9)$

\begin{tabular}{|c|c|c|c|c|c|c|c|c|c|c|c|c|c|c|c|}
\hline \multirow[b]{2}{*}{$\begin{array}{l}\text { Patient } \\
\text { Number }\end{array}$} & \multirow[b]{2}{*}{$\begin{array}{l}\text { Age } \\
\text { (years) }\end{array}$} & \multirow[b]{2}{*}{$\begin{array}{l}\text { Weight } \\
\text { (kg) }\end{array}$} & \multicolumn{2}{|c|}{ SAsat (\%) } & \multicolumn{3}{|c|}{$\begin{array}{l}\text { Pulmonary arterial pressure } \\
\text { (S (M)) } \mathrm{mm} \mathrm{Hg}\end{array}$} & \multicolumn{3}{|c|}{ Aortic pressure $(\mathrm{S}(\mathrm{M})) \mathrm{mm} \mathrm{Hg}$} & \multicolumn{2}{|l|}{ Qp/Qs } & \multicolumn{2}{|c|}{ Rp (Wood) } & \multirow{2}{*}{$\begin{array}{l}\text { Duct } \\
\text { diamete } \\
(\mathrm{mm})\end{array}$} \\
\hline & & & $\begin{array}{l}\text { Before } \\
\mathrm{O}_{2}\end{array}$ & $\begin{array}{l}\text { During } \\
\mathrm{O}_{2}\end{array}$ & Before $\mathrm{O}_{2}$ & During $\mathrm{O}_{2}$ & $\begin{array}{l}\text { After } \\
\text { closure }\end{array}$ & Before $\mathrm{O}_{2}$ & ${ }_{2}$ During $\mathrm{O}_{2}$ & $\begin{array}{l}\text { After } \\
\text { closure }\end{array}$ & $\begin{array}{l}\text { Before } \\
\mathrm{O}_{2}\end{array}$ & $\begin{array}{l}\text { During } \\
\mathrm{O}_{2}\end{array}$ & $\begin{array}{l}\text { Before } \\
\mathrm{O}_{2}\end{array}$ & $\begin{array}{l}\text { During } \\
\mathrm{O}_{2}\end{array}$ & \\
\hline 21 & 32 & 52 & 82.6 & 90.7 & $132(105)$ & 131 (102) & 168 (121) & ) 148 (108) & ) 146 (107) & 130 (108) & 0.66 & 0.83 & 18.81 & 17.68 & 16 \\
\hline 22 & 20 & 53 & 88 & 94.1 & $110(87)$ & $104(87)$ & 135 (91) & $106(86)$ & $100(85)$ & $101(80)$ & 1.49 & 2.75 & 14.26 & 7.45 & 14 \\
\hline 23 & 18 & 50 & 83 & 93 & $106(86)$ & $105(85)$ & 134 (97) & $107(80)$ & $103(80)$ & $90(70)$ & 1.13 & 1.62 & 28.76 & 12.9 & 17 \\
\hline 24 & 28 & 55 & 88 & 99.1 & $112(90)$ & 101 (89) & 121 (92) & 111 (92) & 108 (88) & $106(90)$ & 0.72 & 1.04 & 29.04 & 22.25 & 15 \\
\hline 25 & 26 & 52 & 86 & 96.7 & $103(81)$ & $106(79)$ & $136(92)$ & $113(86)$ & 106 (79) & 113 (93) & 1.09 & 0.89 & 21.35 & 18.75 & 14 \\
\hline $26^{*}$ & 18 & 58 & 95.1 & 99.5 & 135 (101) & 125 (97) & 121 (96) & 139 (99) & 135 (97) & 134 (108) & 1.19 & 2.01 & 29.02 & 21.08 & 18 \\
\hline $27^{*}$ & 18 & 56 & 96.3 & 99.9 & $150(110)$ & 141 (104) & ) 110 (77) & 149 (109) & ) $145(100)$ & $136(106)$ & 1.49 & 2.96 & 17.52 & 6.31 & 14 \\
\hline $28 \dagger$ & 25 & 52 & 95.9 & 98.6 & $93(76)$ & $100(80)$ & $60(45)$ & 140 (92) & 140 (93) & 150 (98) & 2.07 & 2.45 & 7.11 & 6.89 & 12 \\
\hline $29 \dagger$ & 32 & 49 & 97.1 & 99.3 & $65(51)$ & $65(53)$ & $31(25)$ & 105 (79) & 104 (77) & 108 (77) & 4.03 & 7.03 & 1.66 & 1.04 & 10 \\
\hline
\end{tabular}

pulmonary arterial hypertension indirectly, especially for borderline cases. Alhough calculation of pulmonary vascular resistance is also important in assessing the reversibility of pulmonary arterial hypertension, it is less accurate than temporary occlusion of the duct for its unavoidable flaw of pulmonary arterial sample in these patients. Compared with temporary occlusion of the duct with a balloon applied in other reports ${ }^{11}$, we think that trial occlusion with an occluder is simple and convenient.

In this study, we describe the first group report using the Amplatzer occluder for closing PDA with severe pulmonary arterial hypertension in adults. Our findings indicate that transcatheter closure of PDA with severe pulmonary arterial hypertension is feasible, effective and safe in adults. In patients obtaining successful duct occlusion, their mean pulmonary arterial pressures decreased markedly and SAsat was saturated during inhalation of oxygen or after occlusion. For these adult patients, we think that their severe pulmonary arterial hypertension is reversible, and that they can benefit from the closure of PDA. Therefore, occlusion was taken finally. The follow-up of echocardiography confirmed the effectiveness of transcatheter closure of PDA. Among these 20 patients, the SAsat of 14 patients was $<95 \%$ and that of one patient was $<90 \%$ before inhalation of oxygen, which indicates that bidirectional shunts have occurred. This shows that small right-to-left shunts may not relate to the degree of pulmonary vascular disease, and the reversibility of pulmonary arterial hypertension still needs to be assessed. A special case was patient 20. Differential cyanosis was found in the patient, and SAsat was $89.4 \%$ before inhalation of oxygen. Echocardiography showed that mild tricuspid regurgitation occurred. After trial occlusion, the pulmonary arterial pressure decreased markedly, and we found no worsening of signs and symptoms. Therefore, the occluder was released finally under the insistence of the patient. Three months later, although the patient said that she felt better than before occlusion, tricuspid regurgitation deteriorated (systolic velocity of tricuspid valve, $5.7 v 4.4 \mathrm{~m} / \mathrm{s}$ ). Further follow-up is under way.

Oversizing of the duct occluder contributes to increase occlusion rate, especially for patients with large PDA. In this study, the size of the device is selected according to the measurement of the descending aortogram. Usually, the device is $4-10 \mathrm{~mm}$ larger than the narrowest segment of the duct in this study. As the maximum size of the ADO is $16 / 14 \mathrm{~mm}$ and this is too small for large PDA up to $11 \mathrm{~mm}$, the AMVSDO is used. The waist diameter of AMVSDO is 4-10 mm larger than the narrowest size of the PDA. Furthermore, no pulmonic and aortic stenosis caused by occluders occurs in all patients. Although the size of the occluder was large, trace residual left-to-right shunt was found in most patients $10 \mathrm{~min}$ after trial occlusion. After $30 \mathrm{~min}$, only four patients had residual shunt through the device, which disappeared within 2 days after occlusion. No other complications occurred during the procedure.

Increased pulmonary arterial pressures after trial occlusion indicate irreversible severe pulmonary arterial hypertension, which was found in five patients. Cyanosis was obvious in the patients, and SAsat was $<90 \%$ before inhalation of oxygen. In our opinion, Eisenmenger syndromes have occurred, but with little probability of success. Although we suggest that patients undergo palliative treatment, they insist on attempts of transcatheter closure. As a result, they all fail to undergo occlusion owing to increased pulmonary arterial pressures after trial occlusion, and we think that their pulmonary arterial hypertension has become irreversible. The devices of these patients were retracted finally. The lack of proper occluders also resulted in two unsuccessful occlusions in the early period of time. Two other unsuccessful occlusions, where pulmonary arterial pressure had decreased markedly after trial occlusion, were due to the deterioration of dyspnoea. No decrease in aortic pressure was found either, and it seems difficult to explain the phenomenon. In our opinion, the patient may be highly sensitive to the implanted occluder or the sudden decrease in pulmonary blood flow, although his severe pulmonary arterial hypertension was reversible.

\section{Study limitations}

Firstly, the follow-up of most patients lasted for only about 36 months. The main reason for discontinuity was the improvement observed together with the high cost of treatment. Secondly, some measurements of echocardiography were not included in the study-for example, right ventricular volume. This was because the research was retrospective and many measurements were not set before the study.

\section{CONCLUSIONS}

In the adult patients with PDA associated with severe pulmonary arterial hypertension, transcatheter closure of PDA has the potential to differentiate from the reversibility of severe pulmonary arterial hypertension and correct the haemodynamic defect. Further research is required for assessing the long-term results.

\section{Authors' affiliations}

C Yan, S Zhao, S Jiang, Z Xu, L Huang, H Zheng, J ling, C Wang, W Wu, H Hu, G Zhang, Department of Radiology, Cardiovascular Institute and Fuwai Hospital, Chinese Academy of Medical Sciences and Peking Union Medical College, Beijing, China 
Z Ye, H Wang, Department of Echocardiography, Cardiovascular Institute and Fuwai Hospital, Chinese Academy of Medical Sciences and Peking Union Medical College, Beijing, China

Competing interests: None.

Ethical approval: The ethics committee of Fuwai Hospital approved the research.

\section{REFERENCES}

1 Rashkind WJ, Mullins CE, Hellenbrand WE, et al. Nonsurgical closure of patent ductus arteriosus: clinical application of the Rashkind PDA Occluder System. Circulation 1987:75:583-92

2 Verin VE, Saveliev SV, Kolody SM, et al. Results of transcatheter closure of the patent ductus arteriosus with the Botallooccluder. I Am Coll Cardiol 1993;22:1509-14.

3 Hijazi ZM, Geggel RL. Results of anterograde transcatheter closure of paten ductus arteriosus using single or multiple Gianturco coils. Am J Cardiol 1994;74:925-9.

4 Hijazi ZM, Geggel RL. Transcatheter closure of large patent ductus arteriosus (> or $=4 \mathrm{~mm}$ ) with multiple Gianturco coils: immediate and mid-term results. Heart 1996;76:536-40.
5 Uzun O, Hancock S, Parsons JM, et al. Transcatheter occlusion of the arterial duct with Cook detachable coils: early experience. Heart 1996;76:269-73

6 Masura J, Walsh KP, Thanopoulous B, et al. Catheter closure of moderate- to large-sized patent ductus arteriosus using the new Amplatzer duct occluder: immediate and short-term results. J Am Coll Cardiol 1998;31:878-82.

7 Faella HJ, Hijazi ZM. Closure of the patent ductus arteriosus with the amplatzer PDA device: immediate results of the international clinical trial. Catheter Cardiovasc Interv 2000;51:50-4.

8 Thanopoulos BD, Hakim FA, Hiari A, et al. Further experience with transcatheter closure of the patent ductus arteriosus using the Amplatzer duct occluder. J Am Coll Cardiol 2000;35:1016-21.

9 Hosking MC, Benson LN, Musewe N, et al. Transcatheter occlusion of the persistently patent ductus arteriosus. Forty-month follow-up and prevalence of residual shunting. Circulation 1991:84:2313-17.

10 Rao PS, Kim SH, Choi JY, et al. Follow-up results of transvenous occlusion of patent ductus arteriosus with the buttoned device. J Am Coll Cardiol 1999;33:820-6.

11 Thanopoulos BD, Tsaousis GS, Djukic M, et al. Transcatheter closure of high pulmonary artery pressure persistent ductus arteriosus with the Amplatzer muscular ventricular septal defect occluder. Heart 2002;87:260-3.

12 Krichenko A, Benson LN, Burrows P, et al. Angiographic classification of the isolated, persistently patent ductus arteriosus and implications for percutaneous catheter occlusion. Am J Cardiol 1989;63:877-80.

\section{IMAGES IN CARDIOLOGY}

\section{Dynamic left main coronary artery stenosis caused by an aortic aneurysm after aortic valve replacement}

A 69-year-old women with a history of aortic valve replacement two years previously had been admitted to our intensive care unit with a non-ST-segment elevation infarction. Coronary angiography showed a dynamic left main coronary artery stenosis (panels A and B). Aortic angiography revealed a proximal aortic aneurysm with a dimension of $2.0 \times 4.6 \mathrm{~cm}$ (panel C). Transoesophageal echocardiography showed the neck of the aneurysm at the aortic prosthesis with pulse synchronous dynamic compression of the distal left main coronary artery and the proximal circumflex coronary artery (panel D). Subsequently, operative correction was performed without the need for coronary artery bypass grafting.

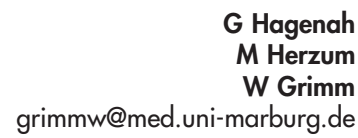

doi: $10.1136 /$ hrt.2006.091025

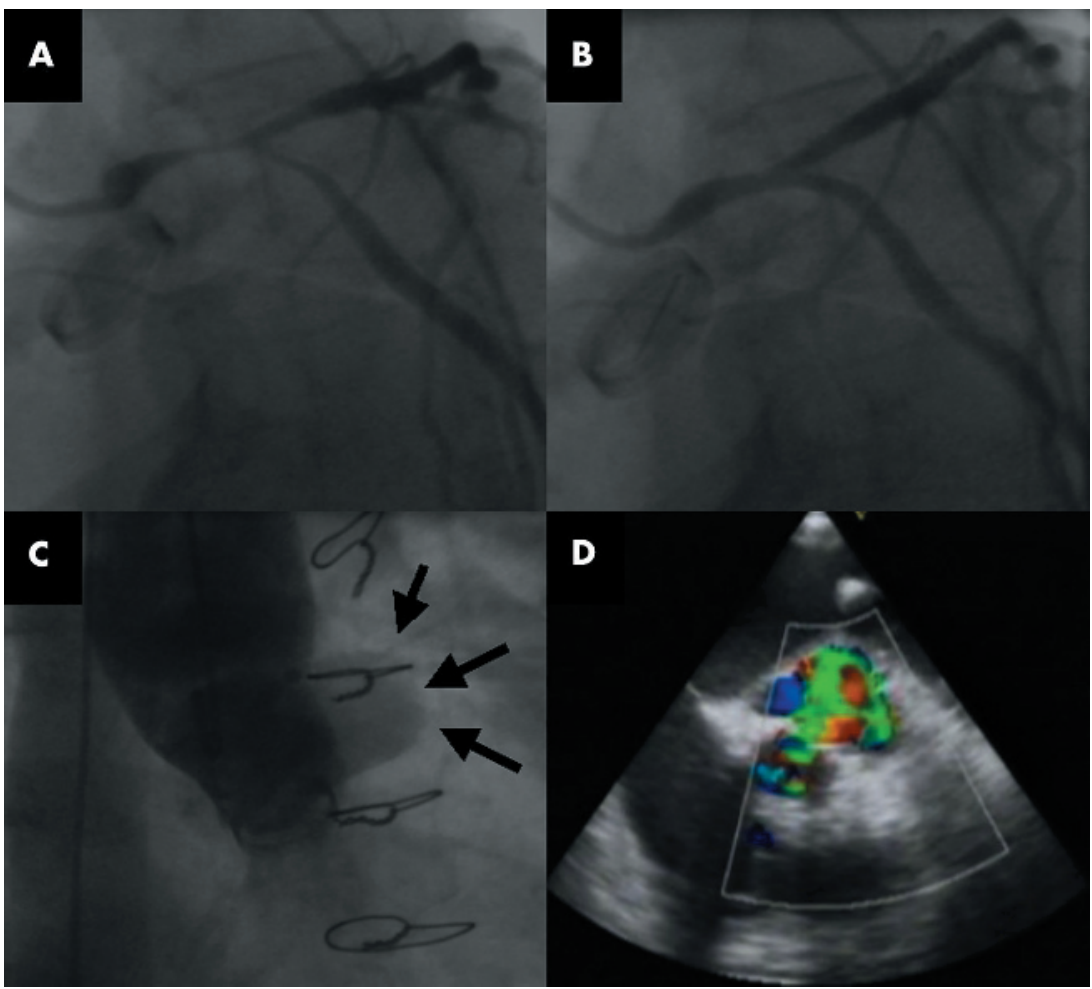

(A and B) Coronary angiography with pulse synchronous dynamic left main coronary artery stenosis. (C) Aortography in the right anterior oblique view denoting the aortic aneurysm (arrows) close to the aortic root. (D) Transoesophageal echocardiography (short axis) with colour Doppler showing the connection. 